\title{
PENERAPAN PRAKTIK KEPERAWATAN BERBASIS BUKTI PURSED LIP BREATHING PADA PASIEN DENGAN PENYAKIT PARU OBSTRUKTIF KRONIK DI RUANG RSU PUSAT PERSAHABATAN JAKARTA
}

\author{
Seven Sitorus \\ Staf Pengajar Fakultas Ilmu-Ilmu Kesehatan Universitas Pembangunan Nasional \\ "Veteran" Jakarta Kampus FIKES UPNVJ, Jl. Limo Raya RT 03/05, Limo, Depok, \\ Jawa Barat - 16515; \\ Email: sevens1973@yahoo.co.id
}

\begin{abstract}
Background: Chronic Obstruction Pulmonary Disease (COPD) is disease characterized by obstruction air flow in the breath not wholly reversible. One treatment can be done on improving exercise tolerance is exercise respiration as pursed lip breathing ( PLB). Purse lip breathing is a techniques of breathing carried out to expelling air by creating power through in move closer /pursed lips. Purpose: provide an illustration of the application of the practice of evidence based nursing of pursed lip breathing in patients COPD in RSUP Persahabatan Jakarta. Method: the implementation of the practice of evidence based nursing pursed lip breathing is applied to 12 people sample ( 10 men and 2 women) diagnosed with COPD exacerbation. Result: the majority of sex respondents is man as many as 10 (83,3\% ) persons and women as many as $2(16,7 \%)$ a person .mean the age of respondents is 61,5 years \pm 10.4 .mean the value of PEF ( Peak Expiratory Flow), the value of the saturation oxygen, the value of respiratori rate before the intervention in a consecutive manner is $131.6 \pm 44.6$; $92.1 \pm 2.44 ; 31.5 \pm 2$. While value after the intervention is 175.0 \pm 60.0; 97,1 $\pm 1.6 ; 22,6 \pm 1.7$ with $P$ value $=0.001, \alpha=0.05$. Conclusions: there are significant influence the application of pursed lip breathing between before and after the intervention in patients COPD. Advice: Intervention evidence based nursing can be applied to all patients COPD so reached the quality of care of nursing based on research .
\end{abstract}

Keywords : COPD, pursed lip breathing.

\section{PENDAHULUAN}

PPOK (Penyakit Paru Obstruktif Kronik) merupakan penyakit yang ditandai dengan hambatan aliran udara di saluran nafas yang tidak sepenuhnya reversibel. Hambatan aliran udara ini bersifat progresif dan berhubungan dengan respons inflamasi paru terhadap partikel atau gas yang beracun atau berbahaya
(Depkes, 2008). Penyakit paru obstruktif kronik ini umumnya disebabkan oleh polusi udara, radang akut saluran pernapasan yang berkepanjangan, radang kronis saluran pernapasan, gangguan sistem imunitas paru, sekret bronkus yang berlebihan (Halim Danusantoso, 2014). Gambaran klinis penyakit paru obstruktif kronik ini adalah: Onset (awal terjadinya penyakit) biasanya 
pada usia pertengahan, perkembangan gejala bersifat progresif lambat, riwayat pajanan, seperti merokok, polusi udara (di dalam ruangan, luar tempat kerja), sesak pada saat melakukan aktivitas, hambatan aliran udara umumnya ireversibel (tidak bisa kembali normal).

PPOK merupakan salah satu penyebab utama kesakitan dan kematian di seluruh dunia. Data hasil Riset Kesehatan Dasar (RISKESDAS) pada tahun 2013 menunjukkan bahwa prevalensi PPOK di Indonesia sebanyak 3,7\%. Prevalensi PPOK diperkirakan akan terus meningkat sehubungan dengan peningkatan usia harapan hidup penduduk dunia, pergeseran pola penyakit infeksi yang menurun sedangkan penyakit degeneratif meningkat serta meningkatnya kebiasaan merokok dan polusi udara. WHO (2013) memprediksi bahwa PPOK yang saat ini merupakan penyebab kematian ke-4 di seluruh dunia diperkirakan pada tahun 2020 akan menjadi penyebab kematian ketiga di seluruh dunia. Sebagai pengingat pentingnya masalah PPOK, WHO menetapkan hari PPOK sedunia (COPD day) diperingati setiap tanggal 18 November.

Hasil studi pendahuluan yang di lakukan penulis melalui unit medical record Rumah Sakit Umum Pusat Persahabatan (2014), terdapat 1280 orang pasien PPOK yang dirawat dan 92 orang pasien yang dilakukan perawatan di IGD selama enam bulan terakhir. Hasil observasi yang dilakukan penulis selama satu bulan pada bulan November 2014 di Instalasi Gawat Darurat pada pasien PPOK yang mengalami eksarsebasi akut ditangani dengan pemberian oksigen, dan obat-obatan bronkodilator melalui nebulizer maupun intravena dan pasien jarang sekali di ajarkan teknik latihan pernapasan seperti pursed lip breathing dan kalaupun diajarkan masih belum ada keseragaman antara satu perawat dengan perawat yang lainnya, hal ini mungkin disebabkan karena belum adanya SOP yang dibakukan mengenai pursed lip breathing.

Melihat peliknya permasalahan pada pasien dengan PPOK, maka penatalaksanaan yang tepat sangatlah 
diperlukan. Tujuan penatalaksanaan pada pasien PPOK ini adalah mencegah progresif penyakit, menghilangkan gejala, memperbaiki status kesehatan, mencegah dan mengobati penyulit, menurunkan mortalitas, mencegah dan mengobati eksaserbasi, memperbaiki exercise tolerance (Slamet H, dkk, 2013).

Salah satu penatalaksanaan yang dapat dilakukan dalam memperbaiki exercise tolerance adalah latihan pernapasan seperti pursed lip breathing (PLB). Purse-lip breathing adalah suatu teknik pernapasan yang dilakukan untuk mengeluarkan udara dengan menciptakan kekuatan melalui merapatkan/memonyongkan bibir (Jadranka Sphahija, Michael de Marchie and Alejandro Grassino, 2005).

Purse-lip breathing sering dilakukan oleh pasien secara spontan, saat purse-lip breathing diaktifkan otot perut selama ekspirasi ternyata dapat memperbaiki pertukaran gas yang dapat dilihat dengan membaiknya saturasi oksigen arteri (John E, Hodgkin., Bartolome R, Celli., Gerilynn L. Connors , 2009).

$\begin{array}{lcr}\text { Purse-lip } & \text { breathing } & \text { juga } \\ \text { memperbaiki } & \text { pola } & \text { nafas, }\end{array}$
meningkatkan volume tidal dan mengurangi sesak nafas. Selain itu PLB juga ditujukan untuk memperbaiki pertukaran gas dan penggunaan otot pernapasan. Manfaat lainnya dari PLB membantu menjaga jalan napas agar tetap terbuka dalam mempertahankan tekanan positip jalan napas. Tujuan lain dari pursed lips breathing ini adalah untuk membantu klien memperbaiki transport oksigen, menginduksi pola napas lambat dan dalam, membantu pasien untuk mengontrol pernapasan, mencegah kolaps dan melatih otototot ekspirasi untuk memperpanjang ekshalasi dan meningkatkan tekanan jalan napas selama ekspirasi, dan mengurangi jumlah udara yang terjebak (Smeltzer \& Bare, 2013).

Pursed-lip breathing ini juga bertujuan untuk memberikan manfaat subjektif pada penderita yaitu mengurangi sesak, rasa cemas dan tegang karena sesak. Pernafasan pursed lip breathing dilakukan dengan cara penderita duduk dan bernafas dengan cara menghembuskan melalui mulut yang 
hampir tertutup (seperti bersiul) selama 4-6 detik. Cara itu diharapkan dapat menimbulkan tekanan saat ekspirasi sehingga aliran udara melambat dan meningkatkan tekanan dalam rongga perut yang diteruskan sampai bronkioli sehingga kolaps saluran nafas saat ekspirasi dapat dicegah.

Pursed lip breathing ini merupakan salah satu terapi intervensi keperawatan non farmakologi dan non invasive yang dapat mengurangi sesak napas (menurunkan frekwensi pernapasan), meningkatkan saturasi oksigen dan meningkatkan arus puncak respirasi. Pursed lip breathing sangat mudah untuk dilakukan, oleh sebab itu penulis tertarik untuk menerapkan Evidence Based Nursing Practice (EBNP)/ praktik keperawatan berbasis bukti tentang Pursed lip breathing ini.

\section{METODE PENELITIAN}

Pelaksanaan praktek keperawatan berbasis bukti yang diterapkan oleh penulis adalah latihan napas dengan metode pursed lip breathing pada pasien PPOK di ruang instalasi gawat darurat RSUP Persahabatan Jakarta. Pasien yang terlibat dalam penerapan praktek keperawatan berbasis bukti ini sebanyak 12 orang ( 10 orang lakilaki dan 2 orang perempuan) yang terdiagnosa PPOK eksarsebasi. Tahap kerja yang dilakukan dengan menggunakan dua metode tergantung dari kondisi pasien tersebut.

Tahap pertama yaitu sambil duduk dikursi, caranya: lipat tangan diatas abdomen, hirup napas melalui hidung sambil menghitung hingga 3, membungkuk ke depan 30 sampai 40 derajat dengan kepala terangkat dengan sudut 16 sampai 18 derajat dan hembuskan dengan lambat melalui bibir yang dirapatkan sambil menghitung hingga 7 . Sedangkan tahap yang kedua yaitu sambil berjalan, caranya: hirup napas sambil melangkah dua langkah, hembuskan napas melalui bibir yang dirapatkan sambil berjalan empat atau lima langkah. Lama waktu yang dibutuhkan untuk melaksanakan tahap kerja adalah 5 sampai dengan 10 menit. Setelah itu baru dilakukan evaluasi untuk pendokumentasian. Adapun evaluasi yang dilakukan adalah dengan mencatat hasil sebelum 
dan sesudah dilakukan intervensi pursed lip breathing mencakup frekwensi pernapasan, arus puncak respirasi (APE) serta saturasi oksigen. Alat yang digunakan untuk mengukur hasil evaluasi yaitu jam tangan, peak flow metry, oksimetri. Berikut hasil penerapan praktek keperawatan berbasis bukti di ruang IGD RSUP Persahabatan Jakarta:

\section{HASIL PENELITIAN}

Tabel 1

Distribusi frekuensi pasien PPOK berdasarkan jenis kelamin Di Ruang IGD RSUP Persahabatan Jakarta $(n=$ 12)

\begin{tabular}{lll}
\hline Variabel & $\begin{array}{c}\text { Jumlah } \\
(\mathbf{n})\end{array}$ & $\begin{array}{c}\text { Persentase } \\
(\boldsymbol{\%})\end{array}$ \\
\hline Jenis & & \\
Kelamin & & \\
Laki - laki & 10 & 83,3 \\
Perempuan & 2 & 16,7 \\
\hline
\end{tabular}

Tabel 1. Menunjukkan mayoritas jenis kelamin responden berjenis kelamin laki - laki sebanyak $10(83,3 \%)$ orang dan perempuan sebanyak $2(16,7 \%)$ orang.
Tabel 2
Distribusi frekuensi pasien PPOK berdasarkan usia, APE (pre dan post), Saturasi Oksigen (pre dan post), RR (pre dan post) di Ruang IGD RSUP Persahabatan Jakarta $(n=12)$

\begin{tabular}{cccc}
\hline Variabel & Mean & SD & $\mathbf{9 5 \%}$ CI \\
\hline Usia & 61.5 & 10.4 & $58.8 ; 68.1$ \\
\hline APE PRE & 13 & 44.6 & $103.2 ; 160.0$ \\
& 1.6 & & \\
\hline APE & 175.0 & 60.0 & $136.8 ; 213.1$ \\
POST & & & \\
\hline $\begin{array}{c}\text { Saturasi } \\
\text { Oksigen } \\
\text { Pre }\end{array}$ & 92.1 & 2.44 & $90.6 ; 93.7$ \\
\hline $\begin{array}{c}\text { Saturasi } \\
\text { Oksigen } \\
\text { Post }\end{array}$ & 97.1 & 1.6 & $96.0 ; 98.2$ \\
\hline RR Pre & 31.5 & 2.1 & $30.1 ; 32.8$ \\
\hline RR Post & 22.6 & 1.7 & $21.5 ; 23-7$ \\
\hline
\end{tabular}

Tabel 2. Menampilkan rata rata usia responden yaitu 61,5 tahun \pm 10,4 (95\% CI : $58.8 ; 68.1)$. Rata rata nilai APE (Arus Puncak Ekspirasi) sebelum intervensi adalah $131.6 \pm 44.6$ (95\% CI: $103.2 ; 160,0)$ dan rata-rata nilai APE setelah intervensi adalah $175.0 \pm 60.0(95 \%$ CI: 136.8 ; 213,1). Rata - rata nilai saturasi oksigen sebelum intervensi adalah $92.1 \pm 2.44$ (95\% CI: 90.6 ; 93,7), dan rata-rata nilai saturasi oksigen setelah intervensi adalah 97,1 $\pm 1,6$ (95\% CI: 96,0 ; 98,2). Rata rata nilai respiratori rate sebelum intervensi adalah $31.5 \pm 2.1(95 \% \mathrm{CI}$ : (95\% CI: $30.1 ; 32,8)$, dan rata-rata 
nilai respiratori rate setelah intervensi adalah $22,6 \pm 1,7$ (95\% CI: 21,5 ; $23,7)$.

Tabel 3

Analisis rata-rata selisih nilai APE, Saturasi Oksigen, RR sebelum dan sesudah dilakukan intervensi Pursed Lip Breathing di Ruang IGD RSUP Persahabatan Jakarta $(n=12)$ breathing sebelum dan sesudah intervensi pada pasien PPOK. Karena nilai $\mathrm{p}<0.05$ maka Ho di tolak. Jadi dapat disimpulkan ada pengaruh yang signifikan antara nilai sebelum dan sesudah penerapan pursed lip breathing sebelum dan sesudah intervensi pada pasien PPOK.

\begin{tabular}{lllll}
\hline Variabel & \multicolumn{1}{l}{ Kelompok } & Mean & SD & P Value \\
\hline Arus & Pre & 131.6 & 44.6 & PEMBAHASAN
\end{tabular}

$\begin{array}{llll}\text { Puncak } & \text { Post } \quad 175.0 & 60.0 & 0,001\end{array}$

Ekspirasi

\begin{tabular}{|c|c|c|c|c|c|}
\hline \multirow{2}{*}{$\begin{array}{l}\text { Saturasi } \\
\text { Oksigen }\end{array}$} & Pre & 92.1 & 2.4 & \multicolumn{2}{|r|}{ isih nilai } \\
\hline & Post & 97.1 & 1.6 & 0, dan & ah intervensi \\
\hline \multirow{2}{*}{$\begin{array}{l}\text { Respiratori } \\
\text { Rate }\end{array}$} & Pre & 31.5 & 2.1 & \multirow{2}{*}{$\begin{array}{l}\text { napas } \\
0,001\end{array}$} & s pursed lip breathing. \\
\hline & Post & 22.6 & 1.7 & & \\
\hline
\end{tabular}

Berdasarkan hasil analisis Hasil penerapan praktik keperawatan pengukuran rata-rata arus puncak ekspirasi sebelum intervensi adalah sebesar $131.6 \pm 44.6$ dan setelah intervensi adalah sebesar $175.0 \pm$ 60.0 ; rata-rata saturasi oksigen sebelum intervensi adalah sebesar $92.1 \pm 2.4$ dan setelah intervensi adalah sebesar 97,2 \pm 1,6; rata-rata respiratori rate sebelum intervensi adalah sebesar $31,5 \pm 2,1$ dan setelah intervensi adalah sebesar 22,6 $\pm 1,7$ dengan 12 responden pada tabel.3 diatas menggunakan uji Dependent $T$ test di dapatkan nilai $\mathrm{P}$ value $=0.001$, yang berarti pada alpha 5\% ada pengaruh penerapan pursed lip berbasis bukti mengenai latihan napas pursed lip breathing terhadap APE, dapat disimpulkan ada pengaruh yang signifikan dengan $\mathrm{p}=0,001, \alpha 0,05$. Hasil ini sejalan dengan penelitian yang dilakukan oleh Jadranka Spahija, Michel De Marchie and Alejandro Grassino, (2005) pada 8 orang pasien PPOK (6 laki-laki dan 2 perempuan) dengan rata-rata $( \pm \mathrm{SD})$ umur 58 tahun \pm 11 tahun dan ratarata arus puncak ekspirasi menit pertama terdiri dari $1,34 \pm 0,44 \pm \mathrm{L}($ $50 \pm 21 \%$ prediksi). Hasilnya: Terdapat hubungan yang signifikan antara PLB dengan sesak napas saat aktivitas terutama pada puncak 
ekpirasi pernapasan dengan nilai estimasi $\quad \mathrm{p}=0,002)$. Kesimpulan: pengaruh PLB pada sesak napas terkait dengan perubahan kenaikan tidal volume dan puncak ekspirasi pernapasan.

Rata-rata selisih nilai saturasi oksigen sebelum dan sesudah intervensi latihan napas pursed lip breathing.

Beranjak pada penerapan praktik keperawatan berbasis bukti mengenai latihan napas pursed lip breathing terhadap saturasi oksigen, dapat disimpulkan ada pengaruh yang signifikan dengan $\mathrm{p}=0,001, \alpha 0,05$. hasil ini sejalan dengan penelitian yang dilakukan oleh G.A.de.F. Fregonezi, V.R.Resqueti, and R.Guell Rous (2004). Pada artikel ini, mereka mereview artikel tentang PLB yang sudah dipublikasikan mulai tahun 1964 sampai dengan 2003 sebanyak 15 penelitian dengan desain RCT (Randomized Clinical Trials) baik menggunakan kontrol group maupun tidak menggunakan kontrol group. Lebih jelasnya, mereka melihat beberapa sesi mengenai salinan tulisan mengenai pengaruh PLB pada fungsi paru dan analisa gas darah, pola pernapasan, dan otot pernapasan. Kesimpulannya: PLB dapat memperbaiki fungsi pernapasan pasien dengan penyakit primer maupun sekunder. Hubungan pola pernapasan dengan prosedur PLB digambarkan terlebih pada masalah psikologis dan ventilasi yang efisien. Adanya tahanan fase ekspirasi pernapasan terutama dikaitkan pada keterlibatan mulut namun secara signifikan perubahan sementara terjadi pada pola pernapasan dan penggunaan otot-otot pernapasan. Hasilnya adalah tidal volume meningkat, penurunan konsumsi oksigen, perbaikan analisa gas darah (saturasi oksigen).

\section{Rata-rata selisih nilai RR sebelum dan sesudah intervensi latihan napas pursed lip breathing.}

Beranjak pada penerapan praktik keperawatan berbasis bukti mengenai latihan napas pursed lip breathing terhadap saturasi oksigen, dapat disimpulkan ada pengaruh yang signifikan dengan $\mathrm{p}=0,001, \alpha 0,05$. Hasil ini sejalan dengan penelitian yang dilakukan oleh Frank J.Visser, Sunil Ramlal, P.N. Richard 
Dekhuijzen, Yvonne F.Heijdra (2010) yang menyatakan nilai rata-rata frekuensi pernapasan menurun secara signifikan dengan $\mathrm{p}<0,001$ dan $\mathrm{SD}$ : 3,1 kali pernapasan/menit, sehingga dapat disimpulkan perbaikan kapasitas inspirasi setelah PLB mengindikasikan berkurangnya sedikit hiperinflasi pada pasien PPOK berat.

\section{KESIMPULAN}

Penerapan praktek keperawatan berbasis bukti pursed lip breathing pada pasien PPOK didapatkan hasil yang efektif sehingga dapat disimpulkan terdapat pengaruh yang signifikan antara pemberian intervensi keperawatan latihan napas pursed lip breathing terhadap arus puncak ekspirasi (APE), saturasi oksigen, dan respiratory rate (RR) dengan $p=0,001, \alpha 0,05$. Namun penerapan latihan napas pursed lip breathing ini mempunyai kelemahan yaitu tidak dapat dilaksanakan bagi pasien yang menggunakan gigi palsu atau ompong, hal disebabkan karena akan mengganggu tiupan pernapasan pasien pada saat ekspirasi maksimal sehingga hasil APE yang didapat tidak akurat.

\section{SARAN}

Intervensi keperawatan berbasis bukti yang sudah diterapkan oleh penulis, dapat dilaksanakan oleh perawat ruangan sehingga dapat meningkatkan kualitas asuhan keperawatan yang diberikan. Namun sebelum diterapkan sebaiknya dibuat dulu standar prosedur operasional (SPO) yang disahkan oleh direktur rumah sakit umum pusat

Persahabatan.

\section{REFERENSI}

Badan Penelitian dan Pengembangan Kesehatan Kemeterian

Kesehatan RI. Laporan Hasil Riset Kesehatan Dasar (RISKESDAS) 2013. LITBANG DEPKES RI.Jakarta.2013.

Depkes (2008). Pedoman Pengendalian Penyakit Paru Obstruktif Kronik Menteri Kesehatan Republik Indonesia, Keputusan Menteri Kesehatan Republik Indonesia Nomor 1022/MENKES/SK/XI/2008.

Frank J.Visser, Sunil Ramlal, P.N. Richard Dekhuijzen, Yvonne F.Heijdra (2010) dengan judul "Pursed Lips Breathing Improves Inspiratory Capacity in Chronic Obstructive Pulmonary disease: clinical 
investigations". Karger AG, Basel. Respiration 2011;81:372378. DOI:10.1159/000319036.

G.A.de.F.Fregonezi， V.R.Resqueti, and R.Guell Rous (2004) dengan judul "Pursed Lip Breathing: Review Article". Arch Bronconeumal 2004;40(6):279-82.

Halim Danusantoso,( 2014). Buku saku ilmu penyakit paru, Edisi 2. Jakarta. EGC.

Jadranka Sphahija, Michael de Marchie and Alejandro Grassino, (2005), Effects of Imposed Pursed Lip Breathing on Respiratory Mechanics and Dyspnea at Rest and During Exercise in COPD. Chest: Aug 2005; 128,2; Proquest Nursing $\&$ Allied Health Source pg.640.

John E, Hodgkin., Bartolome R, Celli., Gerilynn L. Connors
(2009).

Pulmonary

Rehabilitation. USA. Elsevier.

Slamet H, dkk,( 2013). Buku Ajar Ilmu Penyakit paru. Departemen Ilmu Penyakit Paru, FK Unair RSUD Dr. Soetomo. Surabaya.

Rumah Sakit Umum Pusat Persahabatan (2014). Angka Kejadian PPOK. Unit Medical Record.

Smeltzer,S.C., Bare, G.B. (2013). Buku Ajar Keperawatan Medikal Bedah. (Edisi 8 Volume.1). Alih Bahasa: Waluyo, A., dkk, Jakarta; EGC.

World Health Organization (WHO). Chronic Obstructive Pulmonary Disease (COPD). WHO. Geneva. 2013. 